BIODIK: Jurnal IImiah Pendidikan Biologi
ISSN 2580-0922 (online), ISSN 2460-2612 (print)
Volume 7, Nomor 02, Tahun 2021, Hal. 55-62
Available online at:
hIttps://online-journal.unja.ac.id/biodik

Research Article

open 6 Access

\title{
Profil Hasil Belajar Kognitif Siswa Dengan Metode Blended Learning Pada Materi Sistem Pernapasan Manusia
}

\section{(Profile Of Student Cognitive Learning Results With The Blended Learning Method In Human Respiratory System Materials)}

\author{
Ellen Nurlindayani ${ }^{*}$, Setiono, Suhendar
}

Pendidikan Biologi, Fakultas Keguruan dan IImu Pendidikan

Universitas Muhammadiyah Sukabumi

JI. R. Syamsudin, S.H No. 50, Kec. Cikole, Kota Sukabumi, 43113, Indonesia

*Corresponding Author : ellennurlindayanii@gmail.com

\begin{tabular}{|c|c|}
\hline Informasi Artikel & ABSTRACT \\
\hline $\begin{array}{l}\text { Submit: } 03-02-2021 \\
\text { Diterima: } 24-05-2021 \\
\text { Dipublikasikan: } 02-06-2021\end{array}$ & $\begin{array}{l}\text { Cognitive learning outcomes are the student's ability to understand a concept } \\
\text { expressed in a score through a test. Cognitive learning outcomes are important } \\
\text { learning outcomes as the basis for mastery of other abilities. The purpose of this } \\
\text { study was to determine the cognitive learning outcomes of class XI IPA } 2 \text { students on } \\
\text { the material of the human respiratory system. The research method used is a } \\
\text { qualitative method using an instrument in the form of a multiple choice written test. } \\
\text { The research was conducted on March 22, 2021. The subjects of this study were } \\
\text { class XI IPA } 2 \text { with a total of } 30 \text { students. The data obtained is the result of students' } \\
\text { cognitive learning on the material of the human respiratory system. The results } \\
\text { obtained by an average value on the material of the human respiratory system are } \\
27 \% \text { of students in category A, } 17 \% \text { in category B, 30\% with C criteria and } 26 \% \text { with } \\
\text { D criteria. thus providing the achievement of better cognitive learning outcomes, the } \\
\text { obstacle is the lack of direct interaction between educators and students. } \\
\text { Keywords: Cognitive Learning Outcomes, Blended learning }\end{array}$ \\
\hline Penerbit & ABSTRAK \\
\hline $\begin{array}{l}\text { Program Studi Pendidikan Biologi } \\
\text { FKIP Universitas Jambi, } \\
\text { Jambi- Indonesia }\end{array}$ & $\begin{array}{l}\text { Hasil belajar kognitif merupakan kemampuan siswa dalam memahami suatu konsep } \\
\text { yang di nyatakan dalam sebuah skor melalui tes. Hasil belajar kognitif merupakan } \\
\text { hasil belajar yang penting sebagai dasar penguasaan kemampuan lainnya. Tujuan } \\
\text { penelitian ini untuk mengetahui hasil belajar kognitif siswa kelas XI IPA } 2 \text { pada materi } \\
\text { sistem pernapasan manusia. Metode penelitian yang digunakan metode kualitatif } \\
\text { dengan menggunakan instrumen berupa tes tertulis pilihan ganda. Penelitian di } \\
\text { lakukan pada } 22 \text { Maret } 2021 \text {. Subjek penelitian ini adalah kelas XI IPA } 2 \text { dengan } \\
\text { jumlah sebanyak } 30 \text { siswa. Data yang di peroleh merupakan hasil belajar kognitif } \\
\text { siswa pada materi sistem pernapasan manusia. Hasil yang di peroleh rata-rata nilai } \\
\text { pada materi sistem pernapasan manusia yaitu } 27 \% \text { peserta didik berkategori A, } 17 \% \\
\text { berkategori B, } 30 \% \text { berkriteria C dan } 26 \% \text { berkriteria D. Penggunaan metode } \\
\text { Blended learning membantu peserta didik dalam menambah pengetahuan yang lebih } \\
\text { luas, namun kendalanya adalah kurangnya interaksi secara langsung antara pendidik } \\
\text { dan peserta didik. }\end{array}$ \\
\hline & Kata kunci : Hasil Belajar Kognitif, Blended learning \\
\hline
\end{tabular}


This BIODIK : Jurnal IImiah Pendidikan Biologi is licensed under a CC BY-NC-SA (Creative Commons Attribution-ShareAlike 4.0 International License)

\section{PENDAHULUAN}

Ranah kognitif adalah ranah yang berkaitan dengan hasil belajar. Ranah kognitif mencakup C1 (Mengingat), C2 (Memahami), C3 (Mengaplikasikan), C4 (Menganalisis), C5 (Mengevaluasi), C6 (Membuat). Dua aspek di sebut dengan Low Order Thinking dan 4 aspek lainnya disebut High Order Thinking (Sudjana.N, 2010). Setiap Peserta didik memiliki kemampuan kognitif yang berbeda-beda. Kemampuan kognitif yang paling dasar adalah memori jangka panjang, memori jangka pendek dan memori kerja. Perbedaan kognitif antara laki dan perempuan dapat berubah dengan upaya yang dilakukan dan dapat berkembang setiap saat (Hardianti, 2018).

Kemampuan kognitif pada seseorang dapat berbeda-beda, namun bisa berubah dan berkembang setiap saat. Faktor perubahan dapat berupa pengalaman interaksi antara peserta didik dengan lingkungan. Lingkungan sekolah maupun keluarga berpengaruh terhadap hasil belajar kognitif peserta didik sehingga diperlukan upaya yang baik dalam mengembangkan kemampuan kognitif (Ibda, 2015). Hasil belajar merupakan suatu pencapaian atas kemampuan seseorang berdasarkan dari proses perubahan sikap, pengetahuan dan keterampilan. Hasil belajar menurut Bloom dibagi menjadi 3 ranah yaitu kognitif, afektif dan psikomotor. Dari ke tiga ranah tersebut hasil belajar kognitif masih menjadi sorotan publik dan perlu di perhatikan hal ini karena kognitif menekan pada pengetahuan (Ramadhan et al., 2017).

Upaya peningkatan hasil belajar perlu di perhatikan oleh pendidik dalam menggunakan metode yang efektif saat pembelajar tatap muka secara online. Penggunaan Blended learning membantu pendidik dalam menerapkan pembelajaran menggunkan server online yaitu website yang menjadikanya dapat di akses di semua perangkat di mana saja dan kapan saja. Sehingga Blended learning mendukung situasi komunikasi yang terintegrasi secara optimal dan pengalaman belajar dapat mencapai tujuan hasil belajar yang baik. (Setyoko \& Indriaty, 2018).

Hasil belajar kognitif yang baik tidak lepas dari peran seorang pendidik sebagai inovator yang bertanggung jawab dalam inovasi pembelajaran yang dilaksanakan. Dengan kualitas pendidikan yang baik dan penerapan metode yang sesuai maka akan membentuk hasil belajar kognitif yang baik (Handayani et al., 2017). Hasil belajar kognitif menjadi poin yang sangat penting hal ini karena hasil belajar kognitif meliputi tentang aspek pengetahuan dan keterampilan berpikir. Setiap peserta didik perlu memiliki hasil belajar kognitif yang tinggi karena hal tersebut menjadi salah satu standar keberhasilan dalam proses pembelajaran (Ramadhan et al., 2017)

Seiring perkembangan teknologi informasi dan komunikasi di abad ke-21 semakin pesat perkembangannya. Berkembangnya teknologi tersebut sudah berlangsung di segala aspek, salah satunya pada aspek pendidikan. Adanya kemajuan teknologi informasi dan komunikasi dalam pendidikan memberikan kesempatan dalam memenuhi kualitas belajar mengajar yaitu dengan terbukanya akses sumber belajar yang luas. Terutama saat pandemi Covid-19 menimpa Indonesia 
bahkan seluruh dunia. Pembelajaran menggunakan teknologi dapat membantu kegiatan pembelajaran tetap terlaksana (Kurniawati et al., 2019).

Pembelajaran menggunakan Blended learning merupakan pembelajaran yang mengkombinasikan proses pembelajaran melalui kegiatan tatap muka baik offline maupun online. Upaya untuk meningkatkan hasil belajar kognitif perlu adanya metode pembelajaran yang tepat dan fleksibel dalam mengembangkan kognitif peserta didik (Kurniawati et al., 2019). Pada pembelajaran Blended learning peserta didik tidak hanya menerima materi yang diberikan pendidik, tetapi peserta didik juga dapat mengakses materi dari berbagai sumber di internet. Blended learning juga memudahkan pendidik dan peserta didik bertatap muka dengan jarak jauh agar pembelajaran tetap terlaksana (Idris, n.d., 2018)

Menurut para peneliti Blended learning lebih efektif dalam meningkatkan hasil belajar dengan berbantuan teknologi dari pada pembelajaran online dan tatap muka yang dilakukan secara terpisah. Kelebihan pembelajaran dengan metode Blended learning, memberikan pengalaman baru pada saat proses pembelajaran sehingga dapat mengembangkan kognitif peserta didik. Hanya saja kekurangan menggunakan Blended learning adalah tidak meratanya fasilatas yang dimiliki peserta didik (Idris, n.d., 2018). Kegiatan pembelajaran merupakan proses inovasi yang artian selalu adanya perbaikan dan perubahan dalam upaya meningkatkan hasil belajar kogntif peserta didik yang lebih baik (Fiteriani \& Baharudin, 2017). Tujuan di kembangkannya Blended learning adalah untuk meningkatkan pembelajaran lebih aktif baik online maupun offline. Meningatkan kemandirian peserta didik dalam menambah pengalaman belajar sehingga membantu mencapai hasil pembelajaran yang diinginkan (Khoiroh et al., 2017).

Berdasarkan hasil wawancara dari guru biologi kelas XI di SMAN 4 Kota Sukabumi setelah di terapkannya pembelajaran jarak jauh (PJJ) oleh Kemendikbud sebagai situasi darurat dari pandemi Covid-19 terdapat perubahan yang dilakukan dalam pelaksanaan pembelajaran. Dalam upaya mengefektifkan pembelajaran pihak sekolah menggunakan metode Blended learning. Pembelajaran tatap muka di laksanakan menggunakan video conference dan google classroom. Setiap pertemuan dilaksanakan tanya jawab dan diskusi agar siswa dapat memahami materi dan menambah wawasan. Penggunaan google classroom juga sangat fleksibel sehingga mudah di akses kapan saja dan di mana saja sehigga memudahkan peserta didik dalam mendapatkan materi.

Dalam kegiatan pembelajaran guru tidak hanya menyampaikan materi, namun juga siswa ikut berperan aktif dalam pembelajaran seperti berdiskusi, mengerjakan tugas dan mencari sumber materi melalui internet. Pengalaman belajar ini dapat membantu peserta didik dalam menambah pengetahuan dan meningkatkan hasil pembelajaran yang baik. Kemampuan kognitif berbeda-beda setiap individu, sehingga perlu di perhatikan oleh pendidik dalam kegiatan pembelajaran. Mencari upaya dalam mengembangkan dan mengubah kognitif seseorang. Perubahan dapat di laksanakan dengan beberapa cara seperti menggunakan metode yang tepat saat pembelajaran di laksanakan (Handayani et al., 2017). Pada penelitian ini pendidik menggunakan metode Blended learning dalam mengembangkan kognitif peserta didik. 


\section{METODE PENELITIAN}

Metode penelitian yang digunakan yaitu metode deskriptif kualitatif. Penelitian dilaksanakan pada 22 Maret 2021 di kelas XI IPA 2 SMA Negeri 4 Kota Sukabumi sebanyak 30 Siswa. Metode kualitatif merupakan metode penelitian yang di gunakan untuk meneliti pada kondisi obyek yang alamiah (Sugiyono, 2016). Prosedur penelitian terdiri dari 3 tahap yaitu: 1) Tahap persiapan, 2) Tahap pelaksanaan, dan 3) Tahap pengolahan data hasil penelitian.

Pada tahap persiapan dilakukan kajian pustakan, pembuatan surat izin penelitian, memilih subjek penelitian, membuat instrumen penelitian, judgment instrumen dan menyiapkan instrumen berupa tes soal pilihan ganda. Pada tahap pelaksanaan di awali dengan menyebarkan instrumen tes soal pilihan ganda kepada peserta didik. Dan tahap terakhir adalah mengolah data hasil penelitian, kemudian membuat pembahasan dan kesimpulan. Sampel yang digunakan adalah 30 siswa yang telah mempelajari materi sistem pernapasan manusia. Teknik pengambilan sample menggunakan teknik purpose sampling, yaitu teknik pengumpulan sampel dengan pertimbangan tertentu. Pengambilan subjek bukan berdasarkan acak atau daerah tertentu tetapi di dasarkan adanya tujuan tertentu. Penelitian ini dilaksanakan pada 22 Maret 2021.

Pengumpulan data dilakukan dengan menggunakan tes soal pilihan ganda. Tes pilihan ganda yang digunakan 20 soal dengan menggunakan jenjang kognitif mengingat, memahami, mengaplikasikan, menganalisis, mengevaluasi, dan membuat. Dapat dilihat pada Tabel 1.

Tabel 1. Kriteria hasil belajar kognitif

\begin{tabular}{cc}
\hline Tingkat Penguasaan & Skor Standar \\
\hline $90 \%-100 \%$ & $\mathrm{~A}$ \\
$80 \%-89 \%$ & $\mathrm{~B}$ \\
$70 \%-79 \%$ & $\mathrm{C}$ \\
$60-69 \%$ & $\mathrm{D}$ \\
$>59 \%$ & $\mathrm{E}$ \\
\hline
\end{tabular}

Sumber: (Arifin, 2014)

Keterangan :
A : Sangat Baik
B : Baik
C : Cukup
$D$ : Kurang
E : Sangat Kurang 


\section{HASIL PENELITIAN DAN PEMBAHASAN}

Data hasil penelitian peserta didik yang di peroleh dari hasil belajar di tabulasi dan di analisis menggunakan statistik deskriptif. Dapat dilihat pada Tabel 2.

Tabel 2. Hasil analisis skor hasil belajar kognitif

\begin{tabular}{cc}
\hline Uraian & Nilai \\
\hline $\mathrm{N}$ & 30 \\
Min & 65 \\
Max & 95 \\
MediaN & 79 \\
Modus & 65 dan 95 \\
SD & 11,96 \\
Rata-rata & 80 \\
\hline
\end{tabular}

Hasil analisis menunjukan bahwa nilai rata-rata kelas XI IPA 2 adalah 80 Skor tertinggi yang di raih adalah 95 dan skor terendah yang tidak mencapai KKM adalah 65 . Untuk mengetahui tingkat penguasaan peserta didik terhadap hasil belajar kognitif dapat menggunakan acuan tingkat pengkategorian hasil belajar standar lima. Dapat dilihat pada Gambar 1

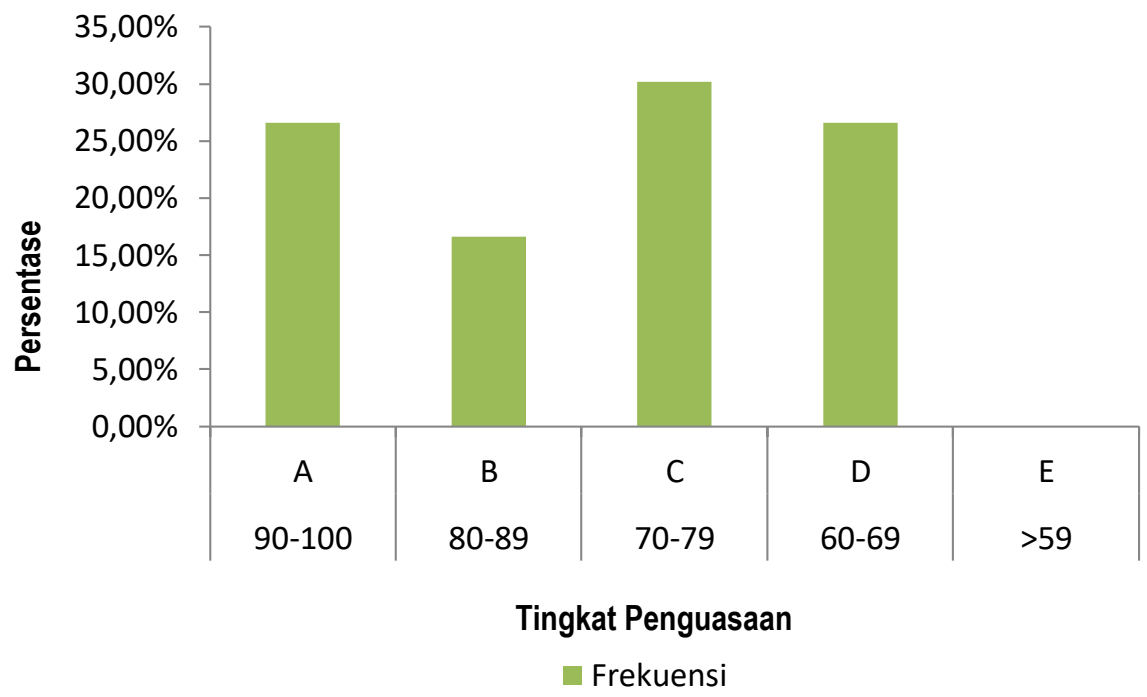

Gambar 1. Grafik frekuensi kategori hasil belajar

Berdasarkan Gambar 1 sebanyak 27\% peserta didik memiliki kategori A, 17\% berkategori B, $30 \%$ berkategori $C, 26 \%$ berkategori $D$, dan $0 \%$ berkategori $E$. Nilai rata-rata yang di peroleh peserta didik laki-laki dan perempuan. Dapat dilihat pada Gambar 2. 


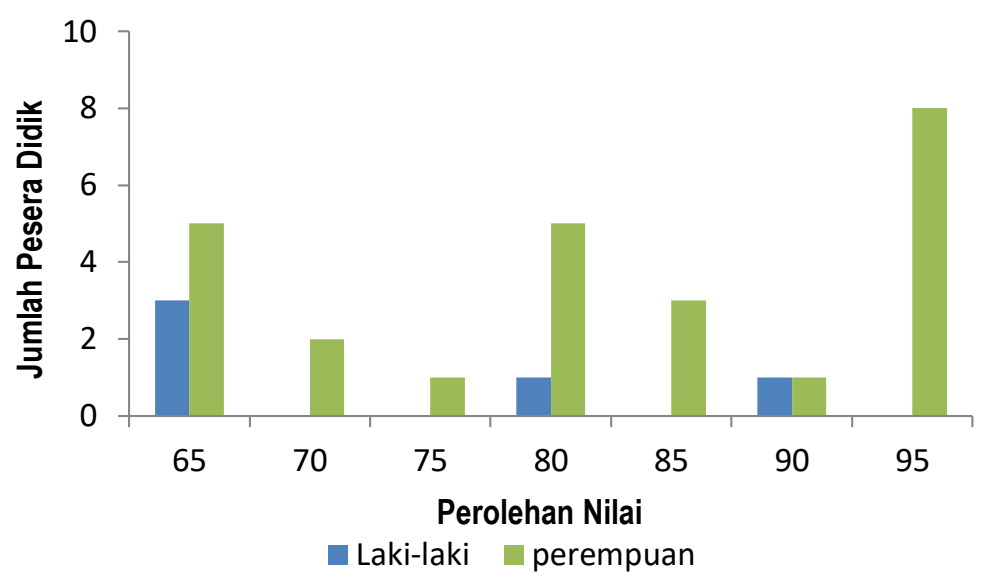

Gambar 2. Grafik Nilai rata-rata peserta didik laki-laki dan perempuan

Berdasarkan Gambar 2, grafik rata-rata nilai 65 pada laki-laki berjumlah 3 orang dan pada perempuan 5 orang. Tidak terdapat peserta didik laki-laki pada nilai 70 sedangkan pada perempuan terdapat 2 orang. Nilai 75 hanya 1 orang untuk perempuan. Nilai 80 terdapat 5 orang perempuan dan 1 laki-laki. Nilai 85 terdapat 3 orang perempuan. Nilai 90 terdapat 1 orang perempuan dan 1 orang lakilaki. Dan nilai tertinggi 95 terdapat 8 orang perempuan. Dari data tersebut perbedaan jenis kelamin mempengaruhi perkembangan kognitif.

Penyampaian materi sistem pernapasan manusia menggunakan metode Blended learning dengan bantuan video conference dan google classroom dalam penelitian ini memiliki potensi dalam meningkatkan hasil belajar kognitif peserta didik. Hal ini terlihat dari hasil analisis skor hasil belajar, yang menunjukan skor tertinggi 95 dan skor terendah 65 sehingga memiliki nilai rata-rata 80. Grafik nilai rata-rata laki-laki dan perempuan, perbedaan jenis kelamin atau gender menunjukan perbedaan dimana perempuan memiliki nilai rata-rata lebih tinggi di bandingkan dengan nilai rata-rata pada laki-laki. Teori skema gender merupakan kategori yang mencerminkan kesan dan keyakinan tentang perilaku apa yang sesuai untuk perempuan dan laki-laki. Perlakuan yang di terima akan berbeda berdasarkan karakter dari perempuan dan laki-laki, hal ini yang memunculkan adanya perbedaan dari hasil belajar kognitif (Suprapto et al., 2018)

Hasil pengamatan sebelumnya peserta didik laki-laki cenderung tidak terlalu memperhatikan atau hirau pada saat kegiatan pembelajaran dilaksanakan, apabila mereka berpikir jika materi yang di jelaskan itu sulit dan tidak menarik. Berbeda dengan peserta didik perempuan yang cenderung lebih tekun dan berusaha dalam memahami materi yang sulit (Hardianti, 2018). Dari hasil penelitian ditemukan adanya perbedaan dari beberapa aspek yaitu laki-laki lebih unggul dalam penalaran visual dimana laki-laki cenderung lebih mudah mencerna informasi lewat apa yang di lihat seperti menarik atau tidak, sulit atau mudah. Sedangkan perempuan lebih unggul dalam komunikasi dan kefasihan kata dimana perempuan lebih memikirkan informasi yang di terima dengan berusaha memamahi setiap kata atau materi yang diterima. Berdasarkan penelitian tersebut menunjuka bahwa kemampuan perempuan lebih tinggi dibandingkan dengan laki-laki dalam ranah kognitif (Nasution, 2011).

Kategori hasil belajar berdasarkan gambar 1 grafik frekuensi kategori hasil belajar, sebanyak $27 \%$ peserta didik memiliki kategori A (Sangat baik), 17\% peserta didik memiliki kategori B (Baik), 30\% peserta didik memiliki kategori C (Cukup) dan 26\% peserta didik memiliki kategori D (Kurang). 
Sebanyak $74 \%$ siswa diatas KKM atau sudah di nyatakan lulus pada materi sistem pernapasan dan sebanyak $26 \%$ tidak mencapai KKM. Setiap peserta didik harus memiliki hasil belajar yang tinggi hal ini karena hasil belajar merupakan standar dalam kerbahasilan seseorang dalam proses pembelajaran. Seperti menurut (Ramadhan et al., 2017) menyatakan keberhasilan proses pembelajaran adalah jika terdapat perubahan tingkah laku dari yang tidak tahu menjadi tahu dan penyempurnaan perkembangan kemampuan yang telah di miliki.

Kemampuan kognitif perlu di perhatikan oleh seorang pendidik dalam meningkatkan hasil belajar yang baik. Untuk membentuk peserta didik yang berkualitas, pendidik dalam penelitian ini menggunakan metode Blended learning dengan tujuan agar pembelajaran tetap terlaksana baik offline maupun online. Penggunaan metode Blended learning lebih fleksibel sehingga meningkatkan peserta didik lebih mandiri dan menambah pengetahuan yang luas (Aslamiyah et al., 2019). Ketika proses pembelajaran online pendidik memfokuskan agar pembelajaran tidak hanya memberikan informasi saja namun adanya interaksi yang lebih aktif dari peserta didik. Pemberian gaya belajar seperti menampilkan visual dan audio meningkatkan keingin tahuan siswa sehingga terjadi diskusi antara peserta didik dengan pendidik ataupun peserta didik dengan peserta didik lainnya (Wardani et al., 2018).

Perkembangan teknologi yang sangat pesat ini dapat di manfaatkan dalam aspek pendidikan. Penggunaan internet dan e-learning ini menjadi salah satu inovasi kegiatan pembelajaran dalam membentuk minat belajar peserta didik dan mempermudah peserta didik dalam mengakses materi atau sumber belajar yang di pelajari (Ahmad, 2017). Penerapan metode Blended learning menurut wawancara bersama guru biologi kelas XI SMA Negeri Kota Sukabumi termasuk efektif di laksanakan saat proses pembelajaran. Hal ini di tunjukan dari hasil belajar kognitif siswa dalam kategori penguasaan sangat baik, baik dan cukup pada materi sistem pernapasan manusia.

\section{SIMPULAN}

Kemampuan kognitif setiap individu berbeda berdasarkan jenis kelamin atau gender. Perbedaan ini dapat berubah dan berkembang berdasarkan perlakuan yang di dapatkan. Hasil belajar kognitif pada penelitian menunjukan perempuan mendapatkan nilai rata-rata yang lebih tinggi di bandingkan dengan laki-laki. Sebanyak $74 \%$ peserta didik dinyatakan lulus dengan nilai mencapai KKM pada materi sistem pernapasan manusia. Kegiatan pembelajaran yang di laksanakan oleh pendidik menggunakan metode Blended learning, metode ini bertujuan untuk membangun siswa agar lebih mandiri, aktif dan memiliki pengetahuan yang lebih luas dalam mencari sumber materi lewat internet. Penggunaan metode Blended learning ini mampu meningkatkan hasil belajar kognitif siswa pada materi sistem pernapasan di kelas XI IPA 2.

\section{RUJUKAN}

Ahmad, K. A. (2017). Analisis Kajian Konseptual Model Pembelajaran Blended Learning berbasis Web dalam Meningkatkan Hasil Belajar dan Motivasi Belajar. Jurnal Pendidikan Edutama, 4(2), 51-64.

Aslamiyah, A. T., Setyosari, P., \& Praherdhiono, H. (2019). Blended Learning Dan Kemandirian Belajar. Jurnal Kajian Teknologi Pendidikan, 2(2), 109-114. https://doi.org/10.17977/um038v2i22019p109

Fiteriani, I., \& Baharudin. (2017). Analisis Perbedaan Hasil Belajar Kognitif Menggunakan Metode Pembelajaran Kooperatif yang Berkombinasi Pada Materi IPA. Jurnal Pendidikan Dan Pembelajaran Dasar, 2(2), 1-30.

Handayani, T., Widyaningsih, S. W., \& Yusuf, I. (2017). Penggunaan model pembelajaran kooperatif 
tipe Snowball throwing terhadap hasil belajar Peserta didik. Curricula: Journal of Teaching and Learning, 2(1), 47-58.

Hardianti, T. (2018). Analisis Kemampuan Peserta Didik Pada Ranah Kognitif Pada Mata Pelajaran Fisika SMA. 25, 557-561.

Ibda, F. (2015). Perkembangan Kognitif Jean Piaget. Intelektualita, 3(1), 242904.

Idris, I. S. (n.d.). Biology Teaching and Learning Analisis Kebutuhan Pengembangan Blended. 101-108.

Khoiroh, N., Munoto., \& Anifah, L. (2017). Pengaruh Model Pembelajaran Blended Learning dan Motivasi Belajar Terhadap Hasil Belajar Siswa. Jurnal Penelitian IImu Pendidikan, 10(2), 97-110.

Kurniawati, M., Santanapurba, H., \& Kusumawati, E. (2019). Penggunaan Metode Blended Learning Menggunakan Model Flipped Classroom Dalam Pembelajaran Matematika SMP. EDU-MAT: Jurnal Pendidikan Matematika, 7(1), 8-19. https://doi.org/10.20527/edumat.v7i1.6827

Nasution. (2011). Berbagai Pendekatan Dalam Proses Belajar dan Mengajar. Bumi Aksara.

Ramadhan, F., Mahanal, S., \& Zubaidah, S. (2017). Meningkatkan Hasil Belajar Kognitif Siswa Melalui Model Pembelajaran Biologi Remap STAD. Jurnal Pendidikan, 2(5), 610-615.

Setyoko, S., \& Indriaty, I. (2018). Penerapan Pembelajaran Problem Based Learning Berbasis Blended Learning terhadap Hasil Belajar Kognitif dan Motivasi Mahasiswa. Jurnal Pendidikan Biologi, 7(3), 157. https://doi.org/10.24114/jpb.v7i3.10433

Sudjana.N. (2009). Penilaian Hasil Proses Belajar Mengajar. Remaja Rosdakarya.

Sugiyono. (2016). Metode Penelitian Kuantitatif, Kualitatif dan R\&D. Bandung: PT Alfabet.

Suprapto, S., Zubaidah, S., \& ... (2018). Pengaruh gender terhadap keterampilan berpikir kreatif siswa pada pembelajaran biologi. ... , Dan Pengembangan, 1, 325-329. http://journal.um.ac.id/index.php/jptpp/article/view/10642

Wardani, D. N., Toenlioe, A. J. E., \& Wedi, A. (2018). Pengembangan Daya Tarik Pembelajaran Di Era 21 Dengan Blended Learning. Jurnal Kajian Teknologi Pendidikan (JKTP), 1(1), 13-18. https://core.ac.uk/download/pdf/287323676.pdf 